\title{
Rapid separation of developing Arabidopsis seeds from siliques for RNA or metabolite analysis
}

\author{
Philip David Bates ${ }^{1,2^{*}}$, Jeremy Burke Jewell ${ }^{1}$ and John Browse
}

\begin{abstract}
Background: Protein, starch and oil produced in plant seeds are major renewable sources of food, chemicals and biofuels. Developing Arabidopsis thaliana seeds are commonly utilized as a model for seed crop research. However, due to the very small size of Arabidopsis seeds efficient collection of large amounts of tissue for gene expression or metabolite analysis is very difficult and time consuming.

Results/conclusions: Here we describe a method that allows very rapid separation and collection of large amounts of developing Arabidopsis seeds from their encapsulating silique tissue after flash freezing whole siliques in liquid nitrogen. The efficient popping open of the frozen siliques on dry ice and filtering the seeds away from the silique tissue with liquid nitrogen cooled funnels and sieves allows large amounts of developing seeds to be quickly isolated while remaining frozen. This method increases the speed of developing seed collection approximately 10 fold over methods which dissect individual siliques one at a time.
\end{abstract}

Keywords: Arabidopsis, Seed, Silique, Gene expression, Dissection, Harvest, Metabolic quench

\section{Background}

Analysis of gene expression or metabolite levels in different tissues of a biological organism is essential to understanding how different tissues function independently from each other. In plants developing seed tissue is the major source of starch, protein, and oils utilized by humans for food, industrial feedstocks or fuel. Therefore accurate analysis of developing seed metabolism is required to understand how these valuable commodities are produced in plants. In the model plant species Arabidopsis thaliana, seeds develop in a non-fleshy fruit tissue known as a silique. The silique tissue has different metabolism and gene expression profiles from the enclosed developing seeds $[1,2]$, and the silique walls contain more tissue on a fresh weight basis than the developing seeds throughout most of silique/seed development. Therefore, to accurately analyze developing seed gene expression or low concentration metabolic intermediates (such as acyl-CoAs) the developing seeds must be removed from the silique. The very small size of developing Arabidopsis siliques and

\footnotetext{
*Correspondence: phil_bates@wsu.edu

${ }^{1}$ Institute of Biological Chemistry, Washington State University, Pullman, WA 99164, USA

${ }^{2}$ Current address: Department of Chemistry and Biochemistry, The University of Southern Mississippi, Hattiesburg, MS, 39406, USA
}

enclosed seeds $(>0.5 \mathrm{~mm},>20 \mu \mathrm{g}$ fresh weight per seed) [3] makes rapid collection of adequate amounts of tissue for gene expression or metabolite analysis very difficult. Dissecting Arabidopsis seeds from siliques can take 1-3 min per silique, depending on the skill of the experimentalist. Therefore, collection of large amounts of developing seed tissue can be very time consuming. Here we present a method that allows efficient separation of the frozen and metabolically quenched seeds from silique tissue after rapidly flash freezing the siliques in liquid nitrogen. Seeds from many siliques may be collected at the same time greatly reducing the time required to collect large amounts of developing seed tissue.

\section{Results and discussion}

The time required to collect all the seeds from 50 developing Arabidopsis siliques by individual silique dissection was approximately 1-2 hrs per person in our hands ( $\sim 6$ individuals, 4 separate attempts). However, our new silique popping method (summarized in Figure 1) allowed us rapidly collect developing seeds from 50 siliques in less than 10 minutes. The silique popping method takes advantage of the fact that developing Arabidopsis siliques soaked in liquid nitrogen will rapidly pop open (like popcorn) when removed from the 


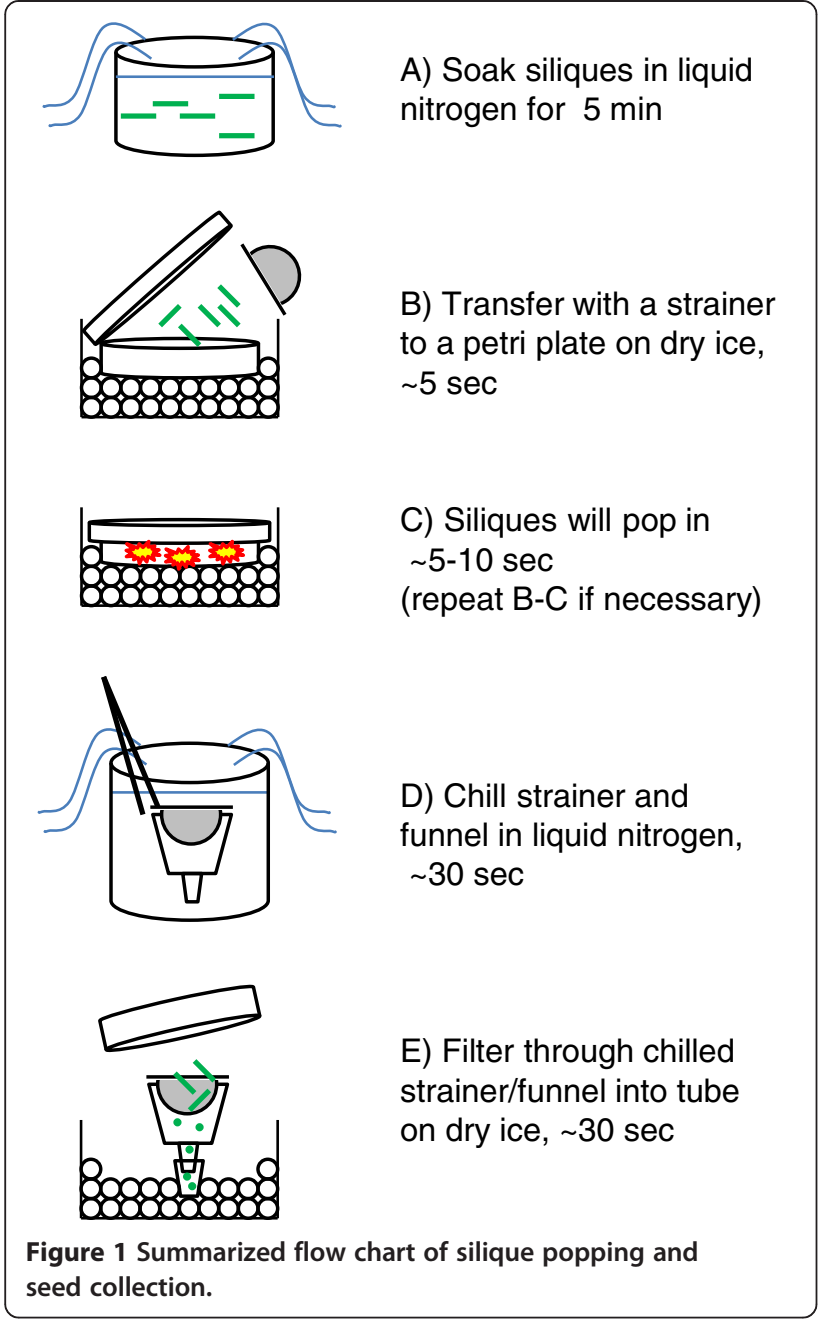

liquid nitrogen (Additional file 1). The popping efficiently separates the seeds from the silique walls. We believe the popping is caused by liquid nitrogen that soaks into the silique and then rapidly expands to a gas creating the pressure to pop open the silique when the silique temperature is raised above that of the liquid nitrogen. By quickly transferring the siliques from the liquid nitrogen bath to a closed container on dry ice the siliques can be efficiently popped open while seed and silique tissue stays frozen. Subsequent filtering of the popped open siliques through a sieve and funnel that has been chilled with liquid nitrogen into a tube on dry ice allows the seeds to be rapidly separated from the silique tissue while remaining frozen (Figure 1). This silique popping method allows the rapid collection of large amounts of developing seed tissue suitable for downstream applications such as RNA extraction. Popping open of $\sim 190$ siliques aged 9-10 days after flowering yielded $\sim 0.8 \mathrm{ml}$ of frozen developing seeds. Three $\sim 0.1-0.2 \mathrm{ml}$ aliquots of developing seed produced 27-38 $\mu \mathrm{g}$ of total RNA each. Our laboratory has successfully utilized this silique popping method to collect sufficient developing seed tissue for gene expression analysis or analysis of very small metabolite pools, such as acyl-CoA, which accumulate at less than $3 \mathrm{pmol} / \mathrm{mg}$ fresh weight [4].

To test the suitability of seeds collected by the silique popping method for downstream applications such as gene expression analysis, we compared RNA quantity, quality and gene expression between developing seeds collected by dissection or by the silique popping method. Ten developing siliques aged to 9-10 days after flowering were dissected directly into $1.5 \mathrm{ml}$ tubes on dry ice [5]. Total RNA extracted from six replicate samples (each containing 10 dissected siliques) averaged $14.2 \pm 1.4 \mu \mathrm{g}$ each. However, when 50 siliques were popped open together and split into six replicates a higher yield of $22.3 \pm 4.4 \mu \mathrm{g}$ RNA was obtained. This higher yield may be due to more seeds in each replicate from a more complete removal of seeds from each silique by the popping method. RNA extracted from frozen seeds collected by the silique popping method was of a consistently high quality suitable for large scale gene expression analysis by RNAseq (Figure 2). Additionally, expression of Arabidopsis genes known to be up-regulated by the handling or touching of plants [6] had low experimental variability within the samples extracted from seeds collected by the popping method (Figure 3).

\section{Conclusion}

Our silique popping method greatly increases the speed ( $>10$ fold) at which large amounts of developing

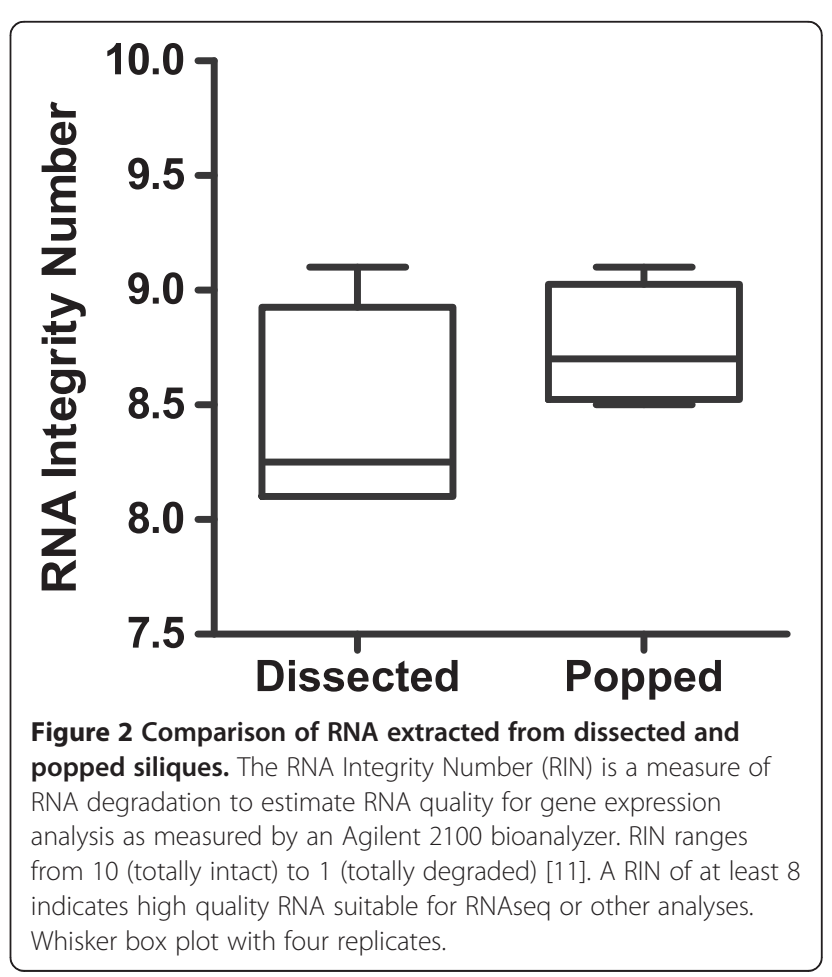




\section{TCH4}
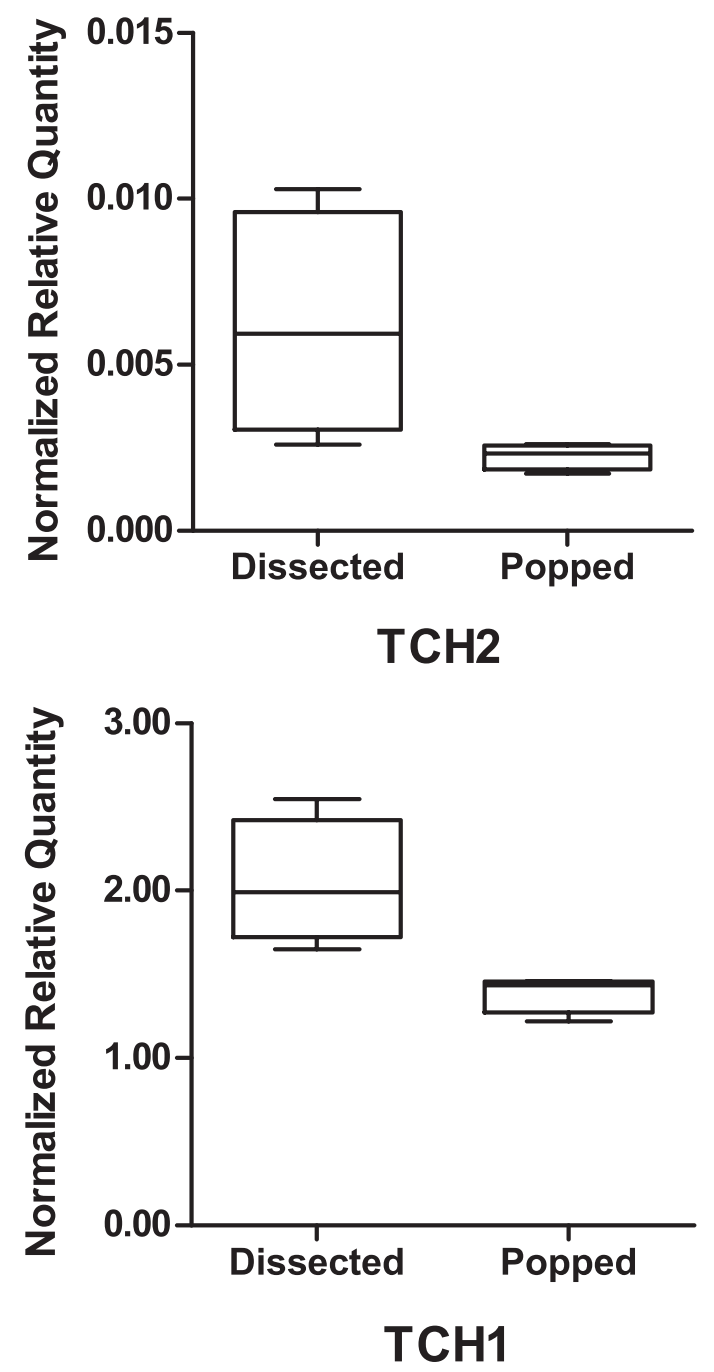

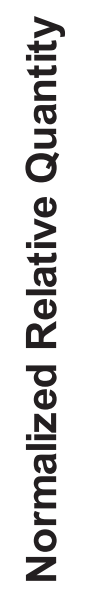

15.0

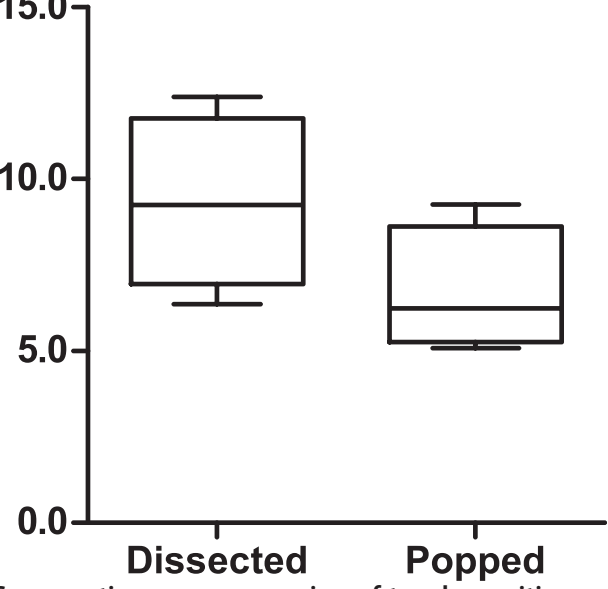

Figure 3 Comparative gene expression of touch sensitive genes. qRT-PCR of three genes $(\mathrm{TCH} 4, \mathrm{TCH} 2, \mathrm{TCH} 1)$ that are responsive to handling or touching of plants [6]. Whisker box plot with four replicates.
Arabidopsis seeds can be collected for subsequent analysis of RNA or other low concentration metabolites. Additionally, the rapid quenching of silique/seed metabolism by harvesting the siliques directly into liquid nitrogen ensures minimal changes in metabolite pools due to tissue disruption during dissection.

\section{Methods}

\section{Silique popping protocol}

\section{Materials}

Liquid nitrogen, a "bed" of dry ice large enough to hold a plastic petri plate, a second dry ice container for $1.5 \mathrm{ml}$ collection tubes, small glass funnel that will fit into $1.5 \mathrm{ml}$ tube, forceps and glass rod, a sieve (or strainer) with pore size large enough for Arabidopsis seeds to fall through (small metal sieves used for straining tea leaves work well).

\section{Safety}

It is important that all normal safety precautions for using liquid nitrogen and dry ice as indicated by their respective MSDS are observed (http://hazard.com/msds/).

\section{Protocol}

1. Harvest developing Arabidopsis siliques directly into liquid nitrogen. Let siliques sit in the liquid nitrogen for at least 5 minutes (Figure 1A).

- Take care not to damage the silique tissue. Remove the siliques from the shoot by cutting the pedicel near the stem.

- Siliques ages of $\sim 8-12$ days after flowering pop open very well.

2. Put a petri plate on a bed of dry ice and let cool for a few minutes, (while siliques are soaking).

- As long as all materials that come in contact with the seeds/siliques are at dry ice temperature or below then the seeds/siliques will stay frozen through each step.

3. Using a liquid nitrogen cooled metal strainer (or forceps) transfer some frozen siliques from the liquid nitrogen to the petri plate on dry ice and immediately put the lid on (Figure 1B).

- Within a few seconds the siliques will start to pop like popcorn (Figure 1C, Additional file 1). The seeds and silique walls that remain in the dry ice cooled dish will remain frozen.

4. Once siliques have popped, remove the lid and repeat until all siliques are the $1.5 \mathrm{ml}$ tube, transferred from the liquid nitrogen bath to the petri plate.

5. Any siliques that do not pop open can be quickly crushed with a liquid-nitrogen-cooled glass rod.

- A thin pair of warm gloves under your lab gloves helps to keep your fingers from freezing while handling liquid nitrogen cooled utensils. 
6. Separate the seeds from the silique tissue by filtering through a liquid nitrogen cooled sieve.

a. Place a $1.5 \mathrm{ml}$ collection tube upright in a second container of dry ice.

b. Put sieve into funnel and dip both into liquid nitrogen together with large forceps (Figure 1D) until the liquid nitrogen stops bubbling rigorously ( 20-30 seconds).

c. Immediately place the cooled sieve/funnel onto the $1.5 \mathrm{ml}$ tube.

d. Immediately pour the frozen seeds/siliques from the petri plate into the sieve/funnel and tap a few times. Most of the seeds will flow into the $1.5 \mathrm{ml}$ tube while most of the siliques will be caught in the sieve (Figure 1E).

- A second straining of the collected seeds through the liquid nitrogen cooled sieve will help remove any silique bits that ended up with the seeds.

7. Once collected the seeds may be stored at $-80^{\circ} \mathrm{C}$ until needed for further analysis.

\section{RNA analysis}

Frozen seed samples were ground to a fine power with a bead beater and RNA extracted by [7], DNA was removed by the DNA-Free RNA Kit (Zymo Research). Total RNA was quantified on a nano-spectrophotometer, values reported are average and standard error. qRTPCR followed standard procedures $[8,9]$ and was normalized to TIP41-like [10]. Primers utilized for RTPCR: qTCH1-f, ATTTGCATGATTGGTGGAGATATG; qTCH1-r, CCATCGGTTTCAATCCAACTTAC; qTCH2-f, GGAAGATTTCGCCGGAGATTAG; qTCH2-r, AGAGCA GAAGATATAGAAACAACCG; qTCH4-f, TCACAAGAG CTTGACTCAACAG; qTCH4-r, TCTTGTTCCTCTCTCA ACTCTTTAC. RNA quality was measured on an Agilent 2100 bioanalyzer [11].

\section{Additional file}

Additional file 1: Popping siliques as in protocol step 3 (Figure 1B,C).

\section{Competing interests}

The authors declare that they have no competing interests.

\section{Authors' contributions}

PB designed/tested the method and wrote the manuscript. JJ tested the method and analyzed RNA prepared utilizing the method. JB gave critical input for method design and manuscript writing. All authors read and approved the final manuscript.

\section{Acknowledgements}

We would like to thank Henrik Tjellström (Michigan State University) for independently testing the method and giving helpful suggestions. This work was supported by the U.S. National Science Foundation (grant no. DBI-0701919) and by the Agricultural Research Center at Washington State University.
Received: 20 February 2013 Accepted: 20 March 2013

Published: 26 March 2013

\section{References}

1. Kleindt C, Stracke R, Mehrtens F, Weisshaar B: Expression analysis of flavonoid biosynthesis genes during Arabidopsis thaliana silique and seed development with a primary focus on the proanthocyanidin biosynthetic pathway. BMC Research Notes 2010, 3:255.

2. Hua W, Li RJ, Zhan GM, Liu J, Li J, Wang XF, Liu GH, Wang HZ: Maternal control of seed oil content in Brassica napus: the role of silique wall photosynthesis. Plant J 2012, 69:432-444.

3. Roeder AHK, Yanofsky MF: Fruit Development in Arabidopsis. The Arabidopsis Book 2006, 4:e0075.

4. Andre C, Haslam RP, Shanklin J: Feedback regulation of plastidic acetylCoA carboxylase by 18:1-acyl carrier protein in Brassica napus. Proc Natl Acad Sci USA 2012, 109:10107-10112.

5. Ruuska SA, Girke T, Benning C, Ohlrogge JB: Contrapuntal networks of gene expression during Arabidopsis seed filling. Plant Cell 2002, 14:1191-1206.

6. Braam J, Davis RW: Rain-, wind-, and touch-induced expression of calmodulin and calmodulin-related genes in Arabidopsis. Cell 1990, 60:357-364.

7. Suzuki Y, Kawazu T, Koyama H: RNA isolation from siliques, dry seeds, and other tissues of Arabidopsis thaliana. Biotechniques 2004, 37:542-544.

8. Udvardi MK, Czechowski T, Scheible W-R: Eleven golden rules of quantitative RT-PCR. The Plant Cell Online 2008, 20:1736-1737.

9. Rieu I, Powers SJ: Real-time quantitative RT-PCR: design, calculations, and statistics. The Plant Cell Online 2009, 21:1031-1033.

10. Czechowski T, Stitt M, Altmann T, Udvardi MK, Scheible W-R: Genome-wide identification and testing of superior reference genes for transcript normalization in Arabidopsis. Plant Physiol 2005, 139:5-17.

11. Schroeder A, Mueller O, Stocker S, Salowsky R, Leiber M, Gassmann M, Lightfoot S, Menzel W, Granzow M, Ragg T: The RIN: an RNA integrity number for assigning integrity values to RNA measurements. BMC Mol Biol 2006, 7:3.

doi:10.1186/1746-4811-9-9

Cite this article as: Bates et al:: Rapid separation of developing

Arabidopsis seeds from siliques for RNA or metabolite analysis. Plant Methods 2013 9:9.

\section{Submit your next manuscript to BioMed Central and take full advantage of:}

- Convenient online submission

- Thorough peer review

- No space constraints or color figure charges

- Immediate publication on acceptance

- Inclusion in PubMed, CAS, Scopus and Google Scholar

- Research which is freely available for redistribution 